\title{
O Texto-Corpo de Al Berto: Imagens de Deleuze \& Guattari
}

\author{
Gustavo Cerqueira Guimarães
}

\begin{abstract}
Resumo
Este ensaio aborda a relação do corpo e do texto na obra do escritor lusitano Al Berto (1948-1997). A opção por analisar o seu livro de estréia, $\dot{A}$ procura do vento num jardim d'agosto (1977), tem o objetivo de facilitar a compreensão do funcionamento geral do "texto-corpo" ao longo de sua trajetória, visto que se encontram ressonâncias marcantes dessa primeira obra.
\end{abstract}

Palavras-chave: Al Berto. Corpo. Escrita. Gilles Deleuze. Félix Guattari.

O "eu" com o qual vou me ocupar não vai ser o "eu" que se refere estritamente a mim mesmo, mas uma outra coisa, um certo resíduo, que permanece depois que todas as palavras que lancei já voltaram para mim. [...] Meditando sobre a natureza desse "eu", fui levado a conclusão que o "eu" em questão coincidia exatamente com o espaço físico que eu ocupava. O que eu procurava, em suma, era uma linguagem do corpo.

Yukio Mishima

[...] por trás de cada poema existe o corpo que o gerou num instante de pânico.

Al Berto

No texto "A literatura portuguesa: dos anos 70 à década de 90", Nuno Júdice esclarece que há duas direções que se sobressaem na escrita da geração de escritores portugueses dos anos de 1970, na qual se inclui Al Berto. Uma é a acentuada reelaboração da tradição literária portuguesa, o que é feito ora pelo excesso ora pelo lado irônico-destrutivo. A outra

[...] está ligada à revalorização do quotidiano, dentro de um novo realismo que já não visa uma denúncia ou crítica de situações sociais, consistindo apenas no retrato nu dessas situações. Nesta linha, com maior ou menor densidade metafórica, vamos encontrar o desenvolvimento de uma poesia do corpo, acentuando a dimensão física da sua relação com o espaço e com os outros. (JÚDICE, 1997, p. 94).

Nessa vertente encontra-se a escrita al-bertiana, em virtude da obstinada presença do significante corpo em toda a obra, articulada ao ato literário. Através do sujeito da enunciação, também escritor - possuidor de um corpo - , Al Berto cria uma 
outra realidade, na tentativa de retratar alguns temas relativos ao homem de seu tempo, todos eles vinculados ao corpo e atrelados à morte, à memória, às artes plásticas ou literárias, à solidão, ao (homo) erotismo, à cidade, à noite, à melancolia, ao mar.

Percebe-se que são vastas as possibilidades de tratar a espacialização do corpo na obra deste escritor, tornando-se até mesmo difícil desmembrar tais instâncias. É necessário, portanto, restringir o foco, pois não se tem a intenção de esgotar as variadas leituras suscitadas, já que o texto al-bertiano se caracteriza pela fragmentação, em que muitas imagens surgem dispersas: "os corpos saem da água vestidos de moluscos vibráteis" (AL BERTO, 2000a, p. 22), "flutuarão astros atrás de nossos corpos oceânicos" (2000a, p. 26), "ventos de fumo azulíneo tingem o melancólico corpo" (2000a, p. 49), "corpo contra corpo, acordados" (2000a, p. 53).

No presente artigo, o foco analisado é o corpo atrelado à escrita em $\grave{A}$ procura do vento num jardim d'agosto (1977), livro de estréia de Al Berto, no qual relaciona-se o modo como corpo e escrita se articulam com o próprio fazer literário. Por um lado, o texto está subordinado ao corpo, e, por outro, não há qualquer distanciamento entre eles. Para abordar tais singularidades, é pertinente ressaltar que, segundo o esclarecimento de Luis Alberto Brandão Santos, "[...] quando se fala de noções associadas ao corpo, ou à experiência sensível, já se está descartando a crença de um 'materialismo' ou 'empirismo' essencialistas. O corpo também é conceito. O sensível também é da ordem do inteligível" (SANTOS, 2002, p. 182-183). Portanto, pode-se tomar o corpo na construção ficcional de Al Berto como hipotético a partir do corpo referencial, pois,

[...] da reconhecibilidade dos condicionadores da experiência sensível, aludidos na narrativa, a ficção pode explorar as margens da própria sensibilidade. Assim, se em seu realismo a narrativa opera por delimitação, já que um corpo hipotético ainda é um corpo, a ficcionalidade opera através do fascínio pelos deslimites, através da elaboração de conjecturas de corpo. (SANTOS, 2002, p. 182-183).

Assim, pode-se avançar na análise da forma como o corpo opera no livro de Al Berto: "a escrita que inventámos evadiu-se do corpo" (2000a, p. 12), "sempre tive medo de quando começo a escrever. só o sangue, o ranho, o suor, têm verdadeira dignidade de tinta" (2000a, p. 12), "os textos possíveis são o despertar do corpo, suas pulsações bruscas, fragmentadas, outros corpos vibram, nomes que acendem desejos. tudo anoto pacientemente" (2000a, p. 26). O sujeito da enunciação está sempre relatando o ato de escrita, sempre falando sobre o seu ofício: "não faço mais nada senão escrever e não estou a preparar as mortais obras completas. vegeto por dentro da minha própria escrita. assumo a produção e a gestão do meu próprio lixo. De qualquer maneira só sei escrever não sei fazer mais nada" (2000a, p. 44).

Para Félix Guattari, o espaço da escrita "[...] é, sem dúvida, um dos mais misteriosos que se nos oferece, e a postura do corpo, os ritmos respiratórios e cardíacos, as descargas humorais nele interferem fortemente" $(2000$, p. 153). Em $\dot{A}$ procura do vento num jardim d'agosto, um determinado momento é especialmente sugestivo de uma consonância com a afirmativa de Guattari, pois o texto de Al Berto parece mesmo configurar-se a partir do corpo, das experiências sensíveis:

é tempo de vigília absoluta. escutar a voz, murmurar estrelas, abrir vermelhas frestas por onde o aparo da caneta injecta sílabas. rasgar o receio coalhado no peito e gritar, gritar até que o grito se perca no silêncio onde nasce a escrita. o corpo é o único suporte do texto. o sangue, o esperma, a vida toda num estremecimento escondido em cada palavra. Chegou o momento de nos alimentarmos com o que segrega o corpo. ranho, suor, mijo, cuspo, merda, o mais repugnante escarro. (...) horas e horas ouvindo os ruídos das 
distantes entranhas vivas, o peido, o arroto, a tosse, convulsa de preferência, e a respiração. (2000a, p. 24).

Nessa passagem, o corpo aparece numa assimetria em relação à escrita, aventando uma anterioridade, pois somente a partir dele é que o texto surgiria. Dessa forma, o escritor concebe o texto partindo do corpo e de suas vicissitudes, no intuito de espelhar estados emocionais e reflexões sobre um cotidiano conturbado, característico das grandes cidades contemporâneas. O corpo funciona também como sustentação do conteúdo, podendo ser visto como tema central da obra.

No entanto, em outro momento, as duas instâncias têm a mesma natureza - "o texto-corpo" - (AL BERTO, 2000a, p. 27), não havendo sequer um distanciamento entre elas, visto que se justapõem: "medo das feridas que alastram pelo interior do corpo, invisíveis, incuráveis como os textos" (2000a, p. 19), "a tinta das palavras é semelhante a esta magra película de esperma ressequido. esgravato-o com a unha e surge um rosto, um corpo dentro doutro corpo" (2000a, p. 20). Esse é um dos motes maiores de toda a obra de Al Berto, na qual corpo-texto se imbricam, retroalimentando-se. Assim, torna-se difícil a distinção entre tais instâncias, sendo desnecessário perguntar de onde vem a sua escrita, pois como Al Berto diz, em O anjo mudo:

[...] havia nele dois mistérios insolúveis: viver e escrever. E ambos estavam tão intimamente ligados que, provavelmente, se conseguisse desvendar um deles, o outro sêlo-ia também. Mas acontece que tinha tentado fazer da sua vida uma obra tão intensa quanto a obra escrita. Por vezes diluíam-se uma na outra, confundiam-se, tão próximas ou afastadas estavam. (2000b, p. 62-63).

Contudo, essa última concepção do corpo e escrita em Al Berto propicia alguns outros desdobramentos, pois o narrador ora mostra-se distante do universo de seus personagens - "lá fora, longe das sílabas inventadas para substituírem à vida, as bichas reproduzem-se a velocidades incríveis. cruzam-se entre elas na esperança de conseguirem uma raça mutante, andrógina" (2000a, p. 24) - ora insere-se nele: "caminho estou sempre a caminhar. viro na próxima rua à direita e atravesso a praceta situada no cruzamento de duas outras ruas. por aqui os chuis fecham os cafés de engate. Perdi de vista Luís e Tóni" (2000a, p. 39). Esse sujeito, portanto, está entre o espaço exíguo dos quartos de pensão e a perambulação do corpo, misturando-se a outros corpos no fluxo vertiginoso das ruas das grandes cidades.

No primeiro caso, o sujeito que se enuncia cria seu próprio mundo "desinteressei-me do que se passava à minha volta" (2000a, p. 28) - e relata as histórias a partir de seu isolamento: "nunca saio da minha cadeira de escritor, detesto viajar e não posso contar-lhe tudo, leitor" (2000a, p. 25). O sujeito revela, assim, uma concepção de escrita que deriva da solidão e, claro, da observação de seu próprio corpo: "[...] durante a noite, escrevo sem continuidade. queimo a noite a observar os pés, as mãos, recuso-me avançar, a mexer-me daqui, recuso-me" (2000a, p. 16). Nesse sentido, o sujeito chega até mesmo ao extremo de dizer que "a viagem é uma predisposição. temos de desejá-la e prepará-la cuidadosamente. viajar sem sair do quarto as malas arrumadas junto à porta. ao fim de uma hora reabro-as e reponho as coisas nos seus lugares. finjo que acabei de chegar" (2000a, p. 41). Conseqüentemente, revela também seus estados emocionais, e suas reminiscências intensificam-se:

reconstruo o quarto de pensão. nele guardei as histórias que me contaram. nele guardo a minha tarimba de monge noctívago a minha selva os meus cadernos de apontamentos e a 
minha solidão. o quarto brilha geme cobre-se de silêncio e de lodo. nele observo meu corpo morrer demoradamente. (2000a, p. 42).

No segundo caso, o personagem-narrador vive à deriva pelas cidades, juntamente com os personagens: "Michel e eu saímos para bebericar um branco seco. a cidade brilhava em néons e jornais luminosos. as avenidas estavam a abarrotar de gente. eu sabia que as cidades são imensas massas de luz flutuante. [...] nunca mais regressei a casa" (2000a, p. 44). Esse corpo que se movimenta em Al Berto não sabe antecipadamente de onde parte e nem para onde vai. Poder-se-ia dizer que equivale ao corpo contemporâneo apontado por Gilles Deleuze:

Ora, hoje se vê que o movimento se define cada vez menos a partir de um ponto de alavanca. Todos os novos esportes - surfe, windsurfe, asa delta - são do tipo: inserção numa onda preexistente. Já não é uma origem enquanto ponto de partida, mas uma maneira de colocação em órbita. O fundamental é como se fazer aceitar pelo movimento de uma grande vaga, de uma coluna de ar ascendente, "chegar entre" em vez de ser origem de um esforço. (1992, p. 151).

Embora o personagem principal que se enuncia em $\grave{A}$ procura do vento num jardim d'agosto se encontre ora nas ruas, ora no confinamento de seu quarto - entre experiências em meio às pessoas e à solidão -, e fale sempre a partir de suas sensações corpóreas, que por vezes se apresentam justapostas e outras vezes assimétricas, não muda a relação corpo-texto. Porém, esse entrelaçamento não impede a distinção entre eles, havendo nessa conjunção " $e$ " "[...] força suficiente para sacudir e desenraizar o verbo ser. Para onde você vai? De onde você vem? Aonde quer chegar? São questões inúteis." [...] buscar um começo, ou um fundamento, implicam uma falsa concepção da viagem e do movimento (metódico, pedagógico, iniciático, simbólico....)" (DELEUZE \& GUATTARI, 2000, p. 37).

Por conseguinte, não importa se o sujeito está dentro ou fora de seu aposento, pois, para além do interior e do exterior, o sujeito escreve o corpo. Para tal efeito, a enunciação se dá pelo uso abundante da primeira pessoa, através de um "eu" que se torna, além de uma simples individualidade, um agenciador coletivo de enunciação. Esse "eu" em Al Berto é consonante com o que Deleuze e Guattari propõem na introdução do livro Mil platôs, na qual apontam um direcionamento ao afirmarem que a questão "[...] não é chegar ao ponto em que não se diz mais EU, mas ao ponto em que já não tem qualquer importância dizer ou não dizer EU" (DELEUZE \& GUATTARI, 2000, p. 11).

No entanto, não se deve pensar que esse "eu" esteja encerrado num corpo, e que este é um ente fechado do qual tudo emana. O corpo, no texto de Al Berto, é relacional e está em constante devir, escrevendo em meio a outras pessoas nas ruas e na solidão de seu quarto, se é que é possível estar absolutamente só. Esse corposujeito está "à procura do vento num jardim d'agosto". A partir das várias derivações do léxico "vento" - sopro, ar, fôlego, respiração, alento, frescor; ou ainda: ventania, furacão, éolo -, essa procura pode ser pensada, por um lado, como um alento. Nesse sentido, o sujeito busca dar algum sentido ao mundo caótico em que vive, através dos registros da escrita, sua linha de fuga criadora (DELEUZE \& GUATTARI, 1977) "consola-me a escrita" (AL BERTO, 2000a, p. 27). Por outro lado, o vento pode ser mesmo apenas a constatação desse mundo caótico, no qual o sujeito da enunciação embarca em seu fluxo e vive à deriva pelas urbes européias em constantes transformações - "meditação do corpo flutuando nos ventos da metamorfose [...] a pausa para tomar um fôlego não existe mais o tempo dum café silencioso" (AL BERTO, 1977, p. 17). Enfim, o autor revela, já neste livro, alguns indícios de complexas 
construções da identidade contemporânea, apresentando um projeto literário que coloca texto e corpo como um dos alicerces fundamentais para a sustentação da obra.

Abstract

This essay focuses on the relation between body and text in the oeuvre of Portuguese writer Al Berto (1948-1997); in particular, in his inaugural piece $\dot{A}$ procura do vento num jardim d'agosto. In analyzing the theme "text-body", the essay also aims to shed light on Al Berto's trajectory as a writer, since arguably this is a theme that resonates throughout his career.

Key words: Al Berto. Body. Writing. Gilles Deleuze. Félix Guattari.

\section{Referências}

AL BERTO. À procura do vento num jardim d'agosto (fragmentos dum exílio) 1974-75. [s.I.]: Alberto R. Pidwell Tavares Editor, 1977.

AL BERTO. À procura do vento num jardim d'agosto. In: 0 medo. 2.ed. Lisboa: Assírio \& Alvim, 2000a. p. 7-66.

AL BERTO. O anjo mudo. Lisboa: Assírio \& Alvim, 2000b.

DELEUZE, Gilles. Conversações. São Paulo: Ed.34, 1992.

DELEUZE, Gilles; GUATTARI, Félix. Kafka: por uma literatura menor. Tradução de Júlio Castañon Guimarães. Rio de Janeiro: Imago, 1977.

DELEUZE, Gilles; GUATTARI, Félix. Mil platôs, capitalismo e esquizofrenia. Tradução de Aurélio Guerra Neto e Célia Pinto Costa. São Paulo: Ed. 34, 2000. v.1.

GUATTARI, Félix. Caosmose - um novo paradigma estético. Tradução de Ana Lúcia de Oliveira e Lúcia Cláudia Leão. São Paulo: Ed. 34, 2000.

GUIMARÃES, Gustavo Cerqueira. À procura do primeiro Al Berto: uma análise da reescrita em "À procura do vento num jardim d'agosto" (1977-1987). In: ALVES, Ida F.; JORGE, Silvio R.; FIGUEIREDO, Mônica (orgs.). No limite dos sentidos, anais do XX Encontro de Professores de Literatura Portuguesa da ABRAPLIP, Instituto de Letras da UFF. Rio de Janeiro: L. Christiano, 2005.

JÚDICE, Nuno. A literatura portuguesa: dos anos 70 à década de 90. In: Viagem por um século de literatura portuguesa. Lisboa: Relógio D'água, 1997.

MISHIMA, Yukio. Sol e aço. Tradução de Paulo Leminski. São Paulo: Brasiliense, 1985.

SANTOS, Luis Alberto Brandão. Teoria do corpo na literatura brasileira contemporânea. In: DUARTE, R.; FIGUEIREDO, V.; 
Em Tese, Belo Horizonte, v. 10, p. 85-90, dez. 2006

FREITAS, V. e KANGUSSU, I. (orgs.). Kátharsis: reflexos de um conceito estético. Belo Horizonte: C/Arte, 2002. p. 182-187. 